\title{
Desafíos para la política exterior en las próximas décadas: Chile y la región en un mundo global
}

\author{
Carlos Portales ${ }^{* * *}$
}

Para responder a la pregunta sobre cuales son los nuevos desafíos para la política exterior de Chile en los próximos años es indispensable situarla en el contexto de la política exterior de los ultimas dos décadas. Los gobiernos de la Concertación (1990-2010) cambiaron la posición internacional de un gobierno políticamente aislado durante los años de régimen militar (19731990), por la de un país con una inserción internacional reconocida y con una creciente, aunque por cierto limitada,

Director del Programa «Organismos Internacionales, Derecho y Diplomacia» de la Escuela de Servicios Internacionales (SIS) y de la Facultad de Derecho de Washington (WCL) de la American University, Washington D.C.

** El autor agradece a Sergio Bitar, Ángel Flisfisch, Marcos Robledo, Alberto Van Klaveren y Augusto Varas sus valiosos comentarios y a Daniela Sepulveda su ayuda en la recolección de información. La responsabilidad por el texto es exclusiva de su autor. capacidad de influencia internacional. La nueva situación ha sido el fruto de la exitosa transición a la democracia, de sus avances económicos y sociales y de su propia política exterior.

La situación de los derechos humanos en Chile estuvo en el foco de la preocupación internacional por casi dos décadas y había pulverizado la imagen de país pequeño que contaba hasta comienzos de los años setenta con una tradición democrática respetada en la escena internacional. El gobierno militar abrió unilateralmente la economía chilena al mercado externo, lo que fue bien recibido en muchos círculos económicos internacionales. Sin embargo, no consiguió dar la confianza suficiente a los inversionistas extranjeros para venir al país: el grueso de la inversión extranjera llego a Chile cuando se restableció el régimen democrático, el país se hacia cargo del legado de violaciones de los derechos humanos, se incorpo- 
raban dimensiones sociales al modelo de desarrollo y el país se reinsertaba internacionalmente ${ }^{1}$.

\section{LA REINSERCIÓN \\ INTERNACIONAL DE CHILE}

La política exterior del Presidente Aylwin (1990-1994) se propuso reinsertar a la nueva democracia en el escenario regional y mundial, otorgándole legitimidad y abrió paso para que durante veinte años el país llegara progresivamente a desarrollar una capacidad de influencia superior a sus dimensiones y a los recursos materiales de que dispone. La política exterior apoyo el proceso de transición, proyectando regional y globalmente los valores de los derechos humanos y la democracia e impulso el desarrollo social para lograr el crecimiento con equidad ${ }^{2}$. La activa política

1 Entre 1981 y 1990 la inversión extranjera directa fue de 5.975 millones de dólares, en el período 1991-2000 alcanzo 36.637 millones de dólares y entre 2001 y 2010 llego a 86.191 millones de dólares. Fuente: <www.direcon.cl>

2 En el ámbito interno se desarrollo una participación política democrática y se incorporo la dimensión social para transformar el modelo de desarrollo en uno de crecimiento con equidad. Como resultado, en veinte años se redujo significativamente la extrema pobreza (del $12,8 \%$ en 1990 al $3,2 \%$ en 2009 ) y se disminuyo la pobreza en el país (del 38,4\% en 1990 al $13,7 \%$ en 2009). Con todo, queda esta tarea por completar y siguen pendientes importantes temas de equidad como la muy desigual distribución del ingreso (el coeficiente de Gini era de 0.57 en 1990 y en 2010 de 0.52 ). comercial internacional de "regionalismo abierto» logro una red de acuerdos de libre comercio que genero una mayor apertura comercial ${ }^{3} \mathrm{y}$ aseguro mercados para el proyecto de crecimiento basado en las exportaciones ${ }^{4}$.

La política exterior del nuevo gobierno democrático desde 1990 dio especial importancia a los derechos humanos y a la defensa y promoción de la democracia, como elementos en los que afincar su legitimidad. La transición a la democracia en Chile coincidió con la caída del muro de Berlín y con la extensión de los valores democráticos en el mundo, de manera que la política exterior chilena se inserto en esa corriente mundial y regional con propuestas innovadoras sustentadas en una visión coherente. El nuevo gobierno democrático chileno propicio en la Organización de Estados Americanos (OEA) la resolución 1080 sobre democracia representativa aprobada en Santiago en junio de 1991, que dio a la oea un nuevo instrumento para la defensa de la democracia en la región y que posteriormente llevaría a la adopción de la Carta Democrática Interamericana en 2001.

En 1989 fue aprobada una reforma constitucional que dio preeminencia a los derechos humanos y que sirvió

3 El comercio exterior representaba en 1995 un $44 \%$ del PIB y en 2008 un 74\% del Рів 4 Durante los primeros años, las negociaciones comerciales regionales y bilaterales fueron criticadas por sectores de opinión publica vinculados a las políticas económicas del gobierno militar con el argumento de que generan «desviación de comercio». 
de marco para la transición. El nuevo gobierno democrático ratifico en Agosto de 1990 la Convención Americana sobre Derechos Humanos (Pacto de San José), retiro las reservas con que el gobierno militar había ratificado en 1988 la Convención contra la Tortura y otras penas crueles, inhumanas o degradantes y reconoció la competencia del Comité de Derechos Humanos del Pacto Internacional de Derechos Civiles y Políticos en 1992. Chile comenzó a actuar proactivamente en los organismos internacionales de derechos humanos y especialmente en la preparación y desarrollo de la Conferencia de las Naciones Unidas sobre Derechos Humanos en Viena (1993), apoyando la creación de Alto Comisionado para los Derechos Humanos, lo que le permitió proyectar la imagen de un país que se preocupa de los valores transgredidos en su historia reciente y que comparte su experiencia con otros países del mundo.

El nuevo gobierno también fue desarrollando progresivamente una nueva política exterior de seguridad que inserto al país en la red de acuerdos de seguridad internacional, de los que por mucho tiempo se había mantenido alejado -como los no proliferación nuclear- enfatizando la importancia de la paz y la seguridad internacional para garantizar su desarrollo. Se promovió el fortalecimiento de la seguridad regional y subregional -especialmente a través de las medidas de fomento de la confianza y la transparencia- contribuyendo a generar nuevas visiones cooperativas entre los países de la región. Chile se propuso especialmente resolver antiguos diferendos con sus vecinos para fortalecer su entorno de paz y seguridad. Durante los años 2000 se avanzo en la participación en las operaciones de Paz, acorde con la nueva posición del país y con sus responsabilidades internacionales.

La política exterior comercial profundizo la estrategia de apertura al exterior tanto a escala global, regional, subregional y bilateral. Las exportaciones de Chile crecieron desde 8.372 millones de dólares, en 1990, hasta 67.798 millones, en 2008, bajando con la crisis el 2009 y recuperándose el 2010. Esta política era necesaria para conseguir un crecimiento sostenido. Durante los veinte años se celebraron tratados comerciales con todos los más importantes socios comerciales que garantizaron el acceso para lo substancial del comercio internacional de Chile a los principales mercados del mundo. La política exterior, en su sentido más amplio, tuvo como propósito crear las condiciones para lograr esas negociaciones y celebrar acuerdos vinculantes regional o bilateralmente con Europa, con Asia-Pacifico, con los Estados Unidos, con Canadá y con los países de América Latina.

Hay que agregar que los mercados de las exportaciones chilenas lograron un mayor equilibrio entre las regiones de destino: así en 1990 Europa concentraba el $51,7 \%$ de las exportaciones chilenas, Asia el 21,4\%, América del Norte el $14,9 \%$, América Latina y el Caribe el $9,6 \%$ y otros mercados el $2,5 \%$; mien- 
tras que en 2008 Asia recibió el 37,3\% de las exportaciones chilenas, Europa el 26,1\%, América del Norte (NAFTA) el $16,9 \%$, América Latina y el Caribe el $16,1 \%$ y otros mercados el 3,6\%.

Como resultado de su proceso de transición pacifica a la democracia, del buen desempeño económico, de la calidad de su democracia y de sus éxitos en el combate contra la pobreza a través de una activa política social y de su política exterior, Chile logro un progresivo reconocimiento internacional que le ha otorgado un grado de influencia superior a sus fuentes de poder basadas en población, territorio y producto, adquiriendo un cierto poder blando ${ }^{5}$. Los gobiernos de la Concertación fueron consultados por las grandes potencias (especialmente Estados Unidos y Europa) en asuntos regionales y en varios casos se recibieron señales de que esperaban un papel más proactivo de la política exterior chilena ${ }^{6}$. Se ha

El concepto de poder blando ( $« s o f t$ power») ha sido desarrollado por Nye (Joseph S. Nye Jr., Soft Power, Public Affairs, New York, 2004) como la capacidad para moldear las preferencias de otros a través de inducción o atracción basada en los valores, la cultura, las instituciones y las políticas de una sociedad. Aunque el estudio esta basado en referencias a grandes potencias, esta noción se puede aplicar a países medianos y aun pequeños, para explicar los recursos que pueden, eventualmente, usar para incidir en el campo exterior.

$6 \quad$ Las reuniones al más alto nivel -Jefe de Estado y Canciller- con gobernantes extranjeros, que fueron intensas durante los cuatro gobiernos de la Concertación, cambiaron de centrarse en los aspectos discutido, con todo, si esa capacidad de influencia ha sido proyectada en toda su potencialidad.

Lo anterior no excluye deficiencias en la implementación, ni limitaciones en la aplicación de esas grandes líneas. Esas orientaciones están contenidas en el primer programa de gobierno de la Concertación ${ }^{7}$, pero su desarrollo fue producto de la experiencia del nuevo gobierno democrático y de los que lo siguieron y de las prioridades que se adoptaron en distintos momentos, influidas por los diversos actores relevantes en el proceso de formulación e implementación de la política exterior.

\section{Chile y América Latina}

La política exterior de la Concertación dio especial importancia a las relaciones vecinales. Con Argentina, se solucionaron tempranamente 23 de los 24 diferendos limítrofes existentes en 1990 y en el único todavía no finalizado se logró un tratado que enmarca su solución. Dos países que habían estado en una situación de pre-conflicto bélico a fines de los años setenta fueron capaces de construir relaciones militares de confianza y hasta establecer una brigada

políticos de la transición interna como fue durante los primeros años hasta un intercambio privilegiado sobre temas regionales -y en muchos casos más allá de la región a medida que se avanzaba en el siglo XXI.

7 Ver <http://www.scribd.com. doc/34195404/Programa-de-GobiernoPatricio-Aylwin> 
conjunta para operaciones de paz. Ambos países transformaron su relación bilateral en una fundamentalmente cooperativa, como quedo reflejado en el Tratado de Maipú de Integración y Cooperación de 2009. Con Perú, se logro en 1999 terminar de cumplir las cláusulas pendientes del Tratado de 1929 y se celebraron importantes acuerdos comerciales, aunque, posteriormente, algunos conflictos de inversionistas chilenos y especialmente la demanda peruana ante la Corte Internacional de Justicia por el limite marítimo agriaron las relaciones bilaterales. Con Bolivia, desde 1990 se desarrollaron crecientes intercambios recíprocos a los más altos niveles -especialmente a través de encuentros bilaterales en los márgenes de reuniones internacionales y en bilateralidad directa después- estableciéndose una agenda permanente de trece puntos que fue conducida con un intercambio franco y constante hasta el 23 de marzo de 2011, en que el presidente Morales anuncio el estudio de una demanda internacional para su reivindicación marítima.

La política exterior chilena en estos veinte años tuvo una participación muy activa en América Latina, incorporándose a diversos foros regionales e influyendo en su conducción y en la construcción de la agenda ${ }^{8}$. En 1990

8 La supuesta dicotomía entre «pro» $\mathrm{O}$ «anti» latinoamericanos, que sesgo una parte del debate político internacional en la Concertación, especialmente en los años 2000, tuvo que ver con el (incompleto) diagnostico de la situación regional y de las posibilidades de Chile para vincularse con los países de América Latina. Con todo, es
Chile se incorporo activamente al Grupo de Río -entonces principal foro de concertación y coordinación política regional- haciéndose cargo de la realización de la Cumbre del Grupo de Río en Santiago en 1993. Posteriormente, Chile volvió a presidir el Grupo el 2002 y a partir de 2010 la Presidenta Bachelet recibió la dirección del Grupo por tercera vez. Desde la Presidencia del Grupo de Río, Chile contribuyó a fortalecer la cooperación política regional y promovió el diálogo entre América Latina y otras regiones.

El apoyo y la participación en las Cumbres Iberoamericanas desde 1991 fortaleció los vínculos con España y con Iberoamérica en un nuevo foro basado en raíces comunes históricoculturales, pero también en intereses económicos muy contemporáneos que España ha desarrollado con la región. La celebración de la VI Cumbre Iberoamericana en 1996 en Santiago y Viña del Mar estuvo centrada en el tema de la democracia, así como la XVII Cumbre en Santiago en 2007 fue enfocada en la protección social, prioridad fundamental para el gobierno de la Presidenta Bachelet. En este contexto, la fluida relación con España ha sido instrumental

preciso reconocer una sensación de cierta distancia entre el proceso de desarrollo chileno -de gran continuidad a través de este período- y las diferencias en el contenido de las políticas publicas implementadas por diversos países de la región, que muchas veces se vieron alteradas producto de crisis o de cambios muy abruptos en las orientaciones de sus gobiernos. 
también para la más amplia vinculación entre Chile y la Unión Europea.

En el ámbito interamericano, hubo aportes significativos a la OEA, que se manifestaron en las Asambleas Generales que se llevaron a cabo en Santiago en 1991 y en 2003, también en torno al tema de la democracia. La importancia que se le dio a esta Organización llevo a la elección del ex Canciller y Ministro del Interior José Miguel Insulza como Secretario General en 2004, así como la alta prioridad otorgada por el gobierno para que nacionales sirvieran en la Comisión y en la Corte Interamericana de Derechos Humanos ${ }^{9}$. La participación constructiva en el proceso de las Cumbres de las Américas desde la I Cumbre en Miami en 1994 y la organización de la Segunda Cumbre en Santiago en 1998 -basada en el tema de la educación, reforma clave para el gobierno del Presidente Frei- reflejan también el papel de Chile como actor significativo en su contribución al sistema interamericano.

El fortalecimiento de los vínculos económico-comerciales con los países de América Latina fue un propósito de la acción exterior del país desde los tempranos años noventa. La red de acuerdos

9 Tres chilenos han sido Presidentes de la Comision Interamericana de Derechos Humanos, los profesores Claudio Grossman, Jose Zalaquett y Felipe Gonzalez, un chileno Vice-Presidente de la Corte Interamericana de Derechos Humanos el profesor Maximo Pacheco, una chilena Presidenta, la profesora Cecilia Medina y actualmente otro abogado chileno es miembro de la Corte. comerciales lograda en la primera parte de la década de 1990 fue precisamente con los países de la región ${ }^{10}$. El alcance de estos acuerdos estuvo determinado por los grados de apertura y por las disciplinas comerciales que las contrapartes estaban dispuestas a aceptar. Por ello Chile no pudo incorporarse originalmente al Mercado Común del Sur (MERcosur), pero lo hizo como miembro asociado en 1996, desarrollando una importante relación comercial con el conglomerado y siendo un activo integrante del llamado mercosur político, que incluye los intercambios sobre diversas políticas sociales. Desde fines de los años noventa se celebraron nuevos acuerdos comerciales bilaterales con países de la región y se profundizaron algunos de los celebrados previamente. Chile también se incorporó como miembro asociado a la Comunidad Andina el 2007. En este contexto, las exportaciones chilenas hacia América Latina aumentaron desde un $12 \%$ el año 1990 a un $17 \%$ el 2010 , habiendo llegado al 22\% el año 2008 antes de la crisis económica mundial. Hay que agregar que la composición de las exportaciones hacia América Latina

10 Chile celebró acuerdos comerciales de distintos grados de profundidad con México en 1992, con Bolivia en 1993, con Venezuela en 1993, con Colombia en 1994, con Ecuador en 1995 y con Mercosur en 1996. Posteriormente, la política de acuerdos comerciales con la región se amplio y en algunos casos se profundizo con nuevos acuerdos: con México (1999), Costa Rica (2002), El Salvador (2002), Panamá (2008), Cuba (2008), Perú (2009), Colombia (2009), Guatemala (2010) y Ecuador (2010). 
es de mayor valor agregado que hacia otros destinos. También aumentaron las importaciones desde América Latina que ha llegado a representar cerca de un tercio de las importaciones totales de Chile. La vinculación económica se ha reforzado puesto que los inversionistas chilenos comenzaron a invertir en el extranjero, principalmente en América Latina $^{11}$.

Desde que Brasil organizara el año 2000 las reuniones sudamericanas, Chile contribuyó activamente en los proyectos de infraestructura y en otros ámbitos de la integración física sudamericana. En el subsecuente proceso de creación de la Unión de Naciones del Sur (UNASUR), Chile propició fórmulas alcanzables a través de la búsqueda de la convergencia entre los procesos de integración económico-comercial existentes, pero después de prolongados intercambios, y debido a la oposición de Venezuela, la idea misma de integración comercial solo logró una mención menguada en el tratado constitutivo. UNASUR se organiza como un organismo cuyas iniciativas deben contar con unanimidad de sus miembros (o al menos la no oposición de ninguno de ellos)

11 De los 56.789 millones de dólares invertidos desde 1990 hasta 2010 por inversionistas chilenos en el extranjero más de un $78 \%$ se ha concentrado en Argentina (15.926 millones), Brasil (11.412 millones), Perú (9.999 millones) y Colombia (8.066 millones). Entre los otros 10 principales receptores están Panamá (814 millones), México (714 millones), Uruguay (702 millones) y Venezuela (596 millones) Fuente: DIRECON <www.direcon.cl>. y su función ha sido más de búsqueda de puntos en común entre gobiernos que sustentan una amplia variedad de políticas y que -todavía- no tienen el sustrato de orientaciones compartidas suficientes, ni la voluntad de ceder las competencias necesarias, para avanzar en un proceso de integración más sustantivo. Con todo, Chile participó con propuestas específicas en todo el proceso de negociación del Tratado de UNASUR y presidió este nuevo referente en 2009, facilitando la solución de conflictos internos en Bolivia y la atenuación de las dificultades entre varios países de la región con motivo del acuerdo colombo-estadounidense sobre uso de bases militares.

Se puede concluir entonces que Chile ha sido desde 1990 activo actor en la región, que ha jugado un papel significativo en los organismos regionales y subregionales y que ha trabajado por una mayor presencia de América Latina en el mundo.

Lo anterior no significa que la integración regional haya avanzado con fuerza. Los más diversos proyectos, en algunos casos contradictorios, fueron propiciados por distintos países, especialmente en este siglo. La lista de referentes es larga: la Comunidad Sudamericana de Naciones, luego UnASUR; la Alternativa Bolivariana para los Pueblos de Nuestra América (ALBA), la ampliación del Grupo de Río y la Comunidad de Estados Latinoamericanos y del Caribe, además de la Comunidad Andina, el mercosur, sin contar los mecanismos de integración de América Central y los del Caribe. 
En este complejo campo, la política latinoamericana de Chile ha contribuido a limar asperezas entre los países de los mecanismos en que participa y a buscar consenso para avanzar, hasta donde sea posible alcanzarlos. Hay que tener presente que en política exterior muchas veces tan importante como lo que se logra es lo que se evita. Siendo América Latina el espacio cercano de Chile y el referente más reconocible en el mundo global, es preciso seguir buscando la armonización de posiciones $y$, en lo posible, avanzar hacia nuevos consensos.

Desde el comienzo de su actuación en el Grupo de Río, Chile contribuyó también con la búsqueda de una proyección de América Latina hacia otros continentes. El acercamiento de la región a Europa se institucionalizó a nivel ministerial en Luxemburgo, en la Primera Reunión Ministerial Institucionalizada de la Comunidad Europea y los países del Grupo de Río en mayo de 1991. En mayo de 1992 se realizó en Santiago la Segunda Reunión Ministerial, que dio un paso fundamental para el fructífero proceso de acercamiento entre los dos grupos que ha vinculado progresivamente a países y a grupos de países de la región con la Unión Europea ${ }^{12}$. La realización de la

12 México (1997) y Chile (2002) tienen Acuerdos de Asociación con la Unión Europea. Los países del Caribe tienen un Acuerdo de Asociación CARIFORUM-CE (2007). Perú y Colombia firmaron recientemente un acuerdo con la UE. Y el MERCOSUR ha renovado en 2010 su interés en una negociación que estuvo estancada por varios años.
Cumbre América Latina y el Caribe Unión Europea ALCUE que se celebrara en 2012 en Chile puede abrir una nueva oportunidad para fortalecer esos vínculos interregionales.

Chile propició también la búsqueda de puentes con Asia: la primera reunión de Cancilleres de la troika del Grupo de Río (Chile, Argentina y Brasil) con Japón en $1993^{13}$ y los contactos con la Secretaria de ASEAN ese mismo año, bajo la Presidencia chilena, estuvieron encaminados en la misma dirección. La incorporación de Chile al APEC en 1995 -después de un largo proceso político de convencimiento a los actores del Asia-Pacífico ${ }^{14}-$, fortaleció la presencia chilena en el más dinámico espacio de

13 El Grupo de Río fue presidido en esa reunión por el Canciller Silva Cimma, acompañado de los Ministros de Relaciones Exteriores de Argentina, Guido di Tella, y de Brasil, Fernando Henrique Cardoso.

14 El proceso de ingreso de Chile al APEC fue producto de un trabajo diplomático sistemático, organizado desde la Cancillería, que involucro la activa participación no solo del Canciller, sino que del Presidente de la Republica, y también de otros Ministros -especialmente del Ministro Secretario General de la Presidencia- con la constante participación de todas las Embajadas acreditadas ante los países de APEC. Fue un largo proceso, que comenzó por justificar el interés chileno por ser parte de este organismo de la Cuenca del Pacifico (no solo en la parte occidental de la Cuenca, sino en Estados Unidos que había dado gran prioridad a su nuevo socio del NAFTA, México.). Luego de más de dos años de perseverante labor en 1993 en Blake Island (Estados Unidos), se logro un acuerdo para incorporar a Chile al año siguiente, en Bogor, Indonesia. Fue una de 
crecimiento del mundo. El acercamiento de ese importante referente a la región fue facilitado por la realización de las Cumbres APEC de 2002 en Los Cabos, México, de 2004 en Santiago y de 2008 en Lima. La dimensión extrarregional de la política exterior chilena contribuyó también a favorecer la vinculación de América Latina con otras regiones, aunque esta no ha sido hecha desde un punto de interlocución único. ${ }^{15}$

Los grandes temas de la política exterior chilena han tenido también una proyección a nivel global. Con el propósito de fortalecer internacionalmente las instituciones de la democracia, Chile se unió en 1995 a la Asociación Internacional para la Democracia y la Asistencia Electoral (IDEA), organismo internacional con sede en Estocolmo que cuenta con 28 estados miembros. También participó desde su inicio, en 1999, en el Grupo Convocante del Foro de Comunidad de las Democracias y realizó la III Reunión Ministerial en Santiago en abril de 2005, dando un activo papel a las organizaciones no gubernamentales en el trabajo de esta coalición. En Naciones Unidas jugó un rol importante en la creación del Fondo para la Democracia.

En el campo social internacional, luego de promover activamente la I Cumbre Mundial de Desarrollo Social

las operaciones diplomáticas más logradas y menos conocidas de este período.

15 Brasil impulso reuniones sudamericanas con la Unión Africana y con los países árabes, en la cuales Chile fue uno de los países de la subregión que participó más activamente. realizada en Copenhague en 1995 , consiguió la elección de Juan Somavía como Director General de la Organización Internacional del Trabajo en 1999. ${ }^{16}$ Bajo su dirección, la oIt se ha reposicionado en el mundo multilateral junto a los grandes organismos económicos y participa de apoyo técnico en el G-20. La creación por los Presidentes Lagos, Chirac y Lula da Silva, junto con el Secretario General de las Naciones Unidas Kofi Annan de la «Iniciativa Contra el Hambre y la Pobreza» configuró una novedoso programa con mecanismos financieros innovadores, como las tasas a los vuelos comerciales internacionales para financiar la lucha contra el Sida y la malaria. La participación chilena ha sido multilateralmente activa, particularmente con la Presidenta Bachelet, en el logro de los Objetivos de Desarrollo del Milenio, especialmente los No. 4 «Reducir la

16 La organización de estas reuniones al nivel de Jefes de Estado y Cancilleres -se ha hecho referencia a 11 en solo 20 años- no solo implica reconocimiento al país anfitrión, sino que le otorga a este un papel muy importante en la determinación de la agenda y en la conducción del conglomerado durante un período que puede ser de un año y que muchas veces trasciende al año de la Cumbre. La sede de una reunión se convierte, para países medianos y pequeños, en espacio privilegiado de acción colectiva multilateral. Por otra parte, la elección de dos dirigentes chilenos para el importante y más antiguo organismo global, la Organización Internacional del Trabajo (OIT) y en la principal organización hemisférica (OEA), son índices adicionales de mayor influencia de la política exterior chilena. 
mortalidad infantil» y No. 5 «Mejorar la salud materna».

En la Conferencia Mundial de Financiamiento para el Desarrollo realizada en Monterrey (México) en 2002, Chile jugó un importante papel en el proceso preparatorio y en su realización el Presidente Lagos propuso abordar la gobernabilidad de la globalización, varios años antes de la crisis económica del 2008 que catapulto el tema al centro de la discusión mundial.

\section{LOS NUEVOS DESAFÍOS Y LA REGIÓN}

¿Cuál es el nuevo contexto en que se plantea la acción internacional de Chile y cuáles son los desafíos para la política exterior chilena después de estos 20 años?

En primer lugar Chile es un país que ha quintuplicado su producto y que ha elevado más de cuatro veces su producto per cápita en veinte años ${ }^{17}$. Aunque el país ha avanzado significativamente en la lucha contra la pobreza, todavía tiene características de desigualdad y exclusión que constituyen no solo un problema social, sino que limitan su crecimiento. La tasa de ahorro e inversión del país sigue siendo baja -especialmente en comparación con las regiones de más crecimiento como Asia del Este. La calidad de la educación todavía no ha progresado decisivamente y su capacidad científico-tecnológica sigue

17 Fuente: The World Bank, <www.worldbank.org>. siendo deficiente. Todas estas características son compartidas -en alguna medida- con una América Latina que, si bien dejó atrás la década perdida de los ochenta y ha enfrentado razonablemente la ultima crisis económica mundial, todavía tiene serios rezagos en materia de desigualdad, exclusión, tasas de ahorro e inversión, calidad de la educación, desarrollo científicotécnico y productividad. Chile -y otros países de América Latina- se encuentran cerca de poder dar un nuevo paso hacia la consolidación de su proceso de desarrollo económico-social. ¿Cuáles son los requerimientos que surgen para su acción exterior, como lo fueron los acuerdos de libre comercio durante los últimos 20 años?

En segundo término, la sociedad chilena ha fortalecido su conciencia de los derechos humanos y de la democracia como fundamento y práctica de su sistema político. ¿De qué manera estos valores deberán plasmarse en la política exterior que se debe implementar y cómo trabajar con los países de la región y más allá en estas materias?

Tercero, Chile ha avanzado significativamente en la resolución de sus problemas vecinales y las diferencias planteadas por Perú están siendo procesadas por la vía jurisdiccional en la Corte de La Haya. Adicionalmente, se ha logrado avanzar en los procesos de fortalecimiento de la confianza y transparencia y en una visión común de la necesidad de la paz para avanzar en el desarrollo. Sin embargo siguen existiendo visiones encontradas con 
Perú y Bolivia ¿Qué líneas seguir o profundizar en la conducción de estos asuntos?

Por último, las preguntas anteriores tienen que responderse en un entorno regional, como se ha señalado. Pero la definición misma de cual es la región está en cuestión. Al comenzar el siglo Xxi los referentes hemisféricos y latinoamericanos han proliferado. Se han agregado instancias subregionales que tienden a superponerse: instancias centroamericanas, caribeñas, andinas, del mercosur y más recientemente sudamericanas y algunas con una fuerte perspectiva ideológica como el ALBA. Y en el proceso de construcción de una voz regional a través el Grupo de Río, paralelamente al momento en que ese mecanismo de consulta y concertación política llegó a ser más incluyente, se levantó la Comunidad de Estados Latinoamericanos y Caribeños. ¿En que forma vincular la política exterior a la región? ¿En cuáles organismos o mecanismos participar? A los temas substantivos comunes hay que agregar los dilemas institucionales -no exentos de preferencias substantivas, por ciertopara organizar la cooperación regional y para proyectar la voz de la región en un mundo global. No solo se trata de definir en que se debe cooperar, sino desde donde se cooperará.

Los referentes subregionales han pasado por altos y bajos: (1) La CARICOM ha sido el proceso más constante. (2) La integración centroamericana estuvo detenida por las guerras especialmente en los ochenta, luego en los noventa volvió a repuntar, pero hoy parece victima de procesos como el de Honduras y del conflicto costarricense-nicaragüense. (3) La Comunidad Andina fue abandonada por uno de sus miembros y se encuentra dividida entre opciones muy diferentes de políticas de desarrollo. (4) El Mercosur ha resistido a los conflictos argentino-brasileños, pero con la posición inconfortable de los miembros más pequeños. Queda la interrogante de si el ingreso de Venezuela contribuirá a una mejor articulación de las políticas de desarrollo del mercosur. (5) Brasil hizo gran hincapié en la opción sudamericana (UNASUR), pero después de la exclusión de la integración comercial en este nuevo organismo, ha mantenido su base económica de negociaciones desde la región en el Mercosur y una mirada propia hacia el mundo global en sus asociaciones con India y Sudáfrica (IBSA) y como potencia global emergente junto al BRIC (Brasil, Rusia, India y China) al que se ha incorporado Sudáfrica, en el BRICs. (6) El ALBA presenta una mayor homogeneidad en sus posiciones alternativas, pero esta alejado de los otros esquemas y funciona sobre la base del financiamiento de un solo país, Venezuela. (7) Y México comienza la nueva década mucho más volcado hacia su compleja situación interna y a la relación con los Estados Unidos.

¿Cómo entender este complejo panorama descrito para diseñar una política hacia la región y desde la región? Es preciso analizar la situación actual de América Latina desde tres 
perspectivas: en relación con las relaciones de poder global, en relación con la inserción internacional de las respectivas estrategias de desarrollo, y en relación con las posibilidades de cooperación intrarregional. Cada una debería aportar elementos para el diseño de una política.

(1) La región comparte la necesidad de reformas al sistema internacional, de manera que las nuevas realidades de la distribución de poder se vean reflejadas en los órganos más importantes del sistema. Sin embargo no hay una posición común acerca de cómo esas reformas deben implementarse, ni menos hay una participación de todos los países de la región en la construcción de las posiciones que se presenten en esos órganos. En la reforma del principal órgano político, el Consejo de Seguridad de las Naciones Unidas, si bien Brasil tiene un importante respaldo en la región para su aspiración a ser miembro permanente, Argentina y México no la apoyan. Otros países de la región han estado abiertos en las negociaciones que se han llevado a cabo en Naciones Unidas a considerar fórmulas intermedias, aunque, como se sabe, el asunto esta estancado.

En relación con la ampliación del G7/8 a G 20, que hoy es el grupo informal post-crisis del 2008 que sirve de campo de negociación de las grandes decisiones financieras y económicas globales, tampoco hay una visión regional propiamente tal. Argentina, Brasil, ni México consultan con la región. Cada uno actúa como país. Y Brasil aparece más coordinado con los BRIC(S). Mientras, otros países de la región -y de más allá de ella- buscan alternativas para que los puntos de vista de los no miembros sean tomadas en cuenta, como las del Grupo de Gobernabilidad Global (GGG), organizado por Singapur y al que pertenece Chile y otros países de la región. Recientemente ex Ministros de Chile, Colombia y Perú han reclamado una participación conjunta de estos países en el G20.

(2) Respecto de los espacios internacionales en que se insertan las estrategias de desarrollo en América Latina, debemos tener en cuenta cuatro tendencias:

- Un grupo de países abiertos, con apertura al comercio internacional y que han desarrollado tratados de libre comercio con sus principales socios comerciales globales (Estados Unidos, la Unión Europea y algunos con países de Asia). Entre estos están México, Chile, Perú, Colombia, los países centroamericanos, Panamá y la República Dominicana

- Un segundo grupo de apertura más limitada, también en proceso de disminución de barreras al comercio internacional, que sin embargo no ha concluido negociaciones con los principales actores comerciales globales -en buena parte porque estos no están dispuestos a negociar comprehensivamente los elementos considerados sustanciales por los principales países de este grupo, como la política agrícola y los sub- 
sidios. Aquí está Brasil y Argentina y el resto del mercosur.

- Un tercer grupo más cerrado, que busca un modelo de desarrollo alternativo a la globalización y se centra principalmente en acuerdos entre Estados y empresas estatales. Es el ALbA de Venezuela, Cuba y en distintos grados Bolivia, Ecuador y Nicaragua.

- Cuarto, los países de la CARICOM que trabajan desde la plataforma de los pequeños Estados insulares, buscando posiciones de excepción a las reglas globales.

(3) En relación con las aéreas de cooperación intrarregional, estas van a estar determinadas por su naturaleza (comercio, energía, transporte, infraestructura, etc.), por la relación geográfica de los países (vecindad), por su nivel de desarrollo, por la compatibilidad de sus políticas, o por una combinación de las anteriores.

Al diseñar una política con América Latina, es preciso tener en cuenta esas dimensiones que inciden en la formulación de la política y tener presente la distinción entre lo deseable y lo posible. En política exterior el resultado no lo determina solo la propia política, sino que es producto de la interacción con la de los otros actores regionales. Pero es importante también la capacidad de crear alternativas -teniendo como parámetros los intereses propios y los intereses de los otros actores regionales- para buscar su potencial convergencia, así como la diplomacia para implementarla.
El desafío político (objetivos) y diplomático (capacidad para conseguirlos) para la política exterior de Chile es desarrollar esta indispensable relación con la región, resguardando sus intereses y teniendo en cuenta los de los otros, de manera de generar nuevos proyectos de ganancia mutua. La presencia internacional de América Latina dependerá de que existan esos proyectos convergentes o, por lo menos, que en algunos temas centrales la región pueda trabajar de consuno. Si se considera un mundo globalizado, la capacidad de participar y competir estará determinada por la maximización de las potencialidades de un número significativo de países de la región.

De ahí que sea necesario determinar cuales son esos intereses, cuales son los elementos que se deben priorizar para avanzar en el proceso de desarrollo, abordando los temas pendientes de pobreza y distribución del ingreso, manteniendo y fortaleciendo el entorno de paz y seguridad, la democracia y la más plena vigencia de los derechos humanos. Se debe determinar cómo la dimensión internacional puede ayudar en esos temas y cómo trabajar la cooperación regional para avanzar hacia esas metas comunes.

La multiplicidad de aéreas temáticas implica un desafío adicional para la relación entre la política exterior y las demás políticas públicas: ¿cómo maximizar la capacidad potencial de influencia del país articulando todos los recursos disponibles? Para ello debe coordinarse la conducción de la política 
exterior con los responsables políticos, financieros, comerciales, así como con los de temas claves -como energía, ciencia y tecnología y conectividaden el aparato público y en los sectores privado y académico. La acción exterior debe ser expresión de los intereses del país y debe ser apoyada por la implementación interna.

Los desafíos comunes de América Latina para avanzar en el proceso de desarrollo pasan hoy por aumentar la inversión en sus economías, por incorporar la innovación científico tecnológica para hacerlas más competitivas; por afrontar las desigualdades e inequidades que caracterizan a las sociedades latinoamericanas y por ampliar la competencia externa ${ }^{18}$. Estos

18 En un reciente estudio encargado por la Comision Andina de Fomento, un grupo de economistas y científicos sociales del Centennial Group International y del Interamerican Dialogue compara el desempeño de América Latina con el de otras regiones del mundo, especialmente Asia del Este, y concluye que, a pesar de los avances de la región, para lograr el desarrollo hay campos en los que hay que lograr sustanciales cambios. Se señala que los países del Asia del Este están más enfocados a los temas del desarrollo que a los asuntos geopolíticos o los debates ideológicos; que han obtenido mayores ganancias en productividad; que tienen más altas tasas de ahorro; que su desarrollo humano esta en el centro de la política y que se premia más el mérito y hay mayores avances en los estándares educacionales; que ha habido mayor inversión publica y privada en infraestructura; que tienen economías más abiertas; que en su proceso de desarrollo han sido capaces de transformar su estructura, convirtiéndose en productores de desafíos comunes tienen dimensiones internacionales que pueden ser enfrentadas a través de proyectos conjuntos o convergentes.

La política exterior debe continuar signada por los valores de la paz, la democracia y los derechos humanos, base de la influencia que tiene Chile- y debe ser congruente con su proceso de desarrollo -teniendo en cuenta sus logros y sus desafíos pendientes-. En una perspectiva regional se debe continuar dando importancia a fortalecer la unidad de la región con esos propósitos y a potenciar su capacidad para vincularse con otras regiones del mundo, desde parámetros compatibles con el sistema de gobierno y con los objetivos de desarrollo chilenos.

En esta dirección es importante articular las relaciones con América Latina y el Caribe en su conjunto con las relaciones subregionales. La comunidad histórica y de valores con América Latina en su conjunto debe fortalecer el espacio latinoamericano que ya tiene reconocimiento universal, constituido por un grupo equilibrado de actores que incluya la participación de Brasil, de México, de Argentina y de

manufacturas; que su distribución del ingreso y otros indicadores sociales son más equitativos; que han formado una clase media innovadora y empresarial que ha aumentado los niveles de consumo interno y que han incrementado significativamente las tasas de comercio intrarregional. Ver: Harinder Kohli, Claudio Loser y Anil Sood, (eds.), Latin America 2040. Breaking Away from Complacency: An Agenda for Resurgence. New Delhi, 2010. 
los demás países de la región. No obstante, la tendencia prevaleciente en los años recientes ha sido a la proliferación de organismos y referentes, sobre distintas bases como las subregionales y las ideológicas. El desafío es recuperar una visión de conjunto que suponga una convergencia sobre bases comunes. En este espacio la presencia de Chile debe constituir un aporte.

La visión regional debe fortalecer los valores comunes. Después del período de dictaduras militares y guerras civiles, el pleno respeto de los derechos humanos y la construcción de democracias solidas continúan siendo predicadas como propósitos de todos. Hay que priorizar los instrumentos que han sido más eficientes. El sistema interamericano de protección de los derechos humanos -solo comparable al europeo en su alcance y eficacia- ha desarrollado una capacidad de responder supletoriamente a las demandas de los habitantes de la región para conseguir la protección de sus derechos. El fortalecimiento de la Comisión y de la Corte Interamericana de Derechos Humanos debe contribuir al pleno funcionamiento del sistema y a consolidar los valores comunes. Las iniciativas subregionales deben concentrarse en la promoción de los derechos humanos.

La promoción de la democracia también es un objetivo compartido, tal como está definido en la Carta Democrática Interamericana y avalado por las cláusulas democráticas vigentes en la mayor parte de los organismos regionales y subregionales. El mejoramiento y la profundización de los instrumentos de observación electoral y los programas de reforma de la gestión del Estado deben contribuir al robustecimiento de las instituciones democráticas independientes y formar parte de la agenda de cooperación regional y hemisférica.

Las distintas realidades geográficas latinoamericanas y las visiones de integración económica - no necesariamente coincidentes como se ha señalado- implican la existencia de diversos niveles de articulación subregional y de varios procesos de integración comercial. El desafío de la política exterior de Chile es obtener los mejores resultados en cada uno de esos ámbitos, articulando su participación en ellos, sin exclusión de ninguno.

Es preciso conjugar la visión regional de América Latina que debe estar presente en la participación de Chile en las instancias globales, la articulación geográfica que servirá para enfrentar temas como el de la interconectividad y las coincidencias en visiones de la inserción económica internacional puede llevar a preferir la articulación con países de la región con los que hay acuerdos de libre comercio bilaterales o de asociación en esquemas subregionales. No se trata de optar por una subregión o por un determinado organismo, sino crear instituciones regionales equilibradas e inclusivas, desde donde Chile y cada país fortalezca su relación con otras regiones. Ello no obsta a desarrollar también instancias subregionales en aquellos ámbitos que sean necesarios para una cooperación más eficaz. 
Para Chile la conectividad entre los países de la región para Chile se ubica principalmente en el ámbito geográfico sudamericano -o del Cono Sur para ser más precisos- y requiere mayores esfuerzos y prioridades nacionales de inversión más altas para avanzar significativamente en un futuro próximo. En el terreno de las políticas públicas, este tema se intersecta con las evaluaciones de proyectos de inversión interna. En esas evaluaciones es preciso darle un valor especial a los proyectos transfronterizos, puesto que siempre se tratará de obras cuyo beneficio se verá en el largo plazo. Y si se quiere fortalecer la integración con el mundo externo esas interconexiones son indispensables. La idea de ser una plataforma de conexión o «puente» entre América Latina y otras regiones pasa en buena medida por esta dimensión, que incluye, entre otros, los ejes transfronterizos (conectividad Atlántico-Pacífico) y los regímenes de libre tránsito, indispensables para que los adelantos físicos puedan servir a sus propósitos de conectar. Chile será plataforma si puede conectar y vincularse más estrechamente con Argentina y con los otros países del Cono Sur.

El abastecimiento de energía es un elemento clave que condiciona el crecimiento económico. Es un tema en que están pendientes grandes definiciones nacionales. Ya se intentó un primer gran proyecto energético con Argentina a mediados de los años noventa, que duró una década y que fallo por el cambio de las condiciones y las políticas económicas en el país vecino y por sus nuevas prioridades, así como por la fragilidad de los acuerdos que lo ampararon. Las posibilidades de acceder con seguridad a los recursos energéticos de los países de la región - horizonte clave para la integración regional- aparece todavía lejana y la capacidad de lograr acuerdos vinculantes todavía no tiene bases políticas ni jurídicas sólidas. Sin embargo, es de interés de Chile seguir trabajando en esta dirección. De ahí la importancia de las políticas vecinales y de la cooperación regional. Con todo, hay que otorgar especial prioridad a la cooperación internacional -con y más allá de la región- para facilitar cambios en la matriz energética, de manera de desarrollar fuentes alternativas y con sustentabilidad ambiental. Contar con las tecnologías apropiadas es clave para avanzar en esta dirección, condición sine qua non para el proceso de desarrollo. Aquí hay una tarea crucial para la acción exterior que requiere una vez que las definiciones en este campo se concreten, entre otras condiciones, una mejor coordinación entre la Cancillería y el Ministerio de Energía a fin de conseguir las tecnologías y las inversiones adecuadas.

La ciencia y tecnología y su aplicación a los procesos productivos son cruciales para el desarrollo futuro, en el que la matriz productiva tenga un mayor valor agregado. También aquí, para implementar las necesarias definiciones de políticas públicas, se requerirá de una mejor y más fluida respuesta de las instituciones nacionales a las posibilidades ya abiertas a través de los 
acuerdos existentes (especialmente con Europa y Estados Unidos ${ }^{19}$ ) y mejorar el intercambio, usando coordinadamente el aparato publico externo e intern. Una adecuada modernización del aparato público en este ámbito, debidamente articulado con la academia y el sector privado es imprescindible para conseguir resultados.

Una visión de las necesidades nacionales más precisa puede ser encauzada con el apoyo del aparato exterior chileno ${ }^{20}$ y acelerar los tiempos en una tarea que es, por lo menos, de mediano aliento. El privilegiar la cooperación regional en esta dirección ha sido, hasta ahora, principalmente retórica. Aquí hay otro desafío pendiente para la integración regional.

La profundización del libre comercio seguirá siendo un tema importante de la política exterior. Chile podría retomar su influencia en estas materias a nivel global (especialmente en la OMC) y

19 Nos referimos a Acuerdos de Ciencia y Tecnología y a otras posibilidades abiertas en los tratados de Asociación y de libre comercio, pero también a la necesidad de la cooperación para mejorar herramientas más básicas como la enseñanza del inglés - prioridad impulsada por el Ministro de Educación Sergio Bitar a mediados de la década pasada-, la difusión y uso del Internet, y el Programa de Becas de postgrado que creo el Canciller Alejandro Foxley.

20 La Cancillería en 2006 creo una Dirección de Ciencia y Tecnología que ha creado vinculos con el resto del aparato público y con instituciones académicas y privadas. Se trata de una de las innovaciones más promisorias realizadas en el Ministerio de Relaciones Exteriores durante el período de la Concertación. debe continuar sus intentos de avanzar con países afines (completar el Acuerdo de Asociación Transpacífico ampliando el P4 a Australia, Estados Unidos, Malasia, Perú y Vietnam, por ejemplo). Una nueva etapa con Europa requiere una mejor capacidad de aprovechamiento interno de los acuerdos vigentes a fin de ser contraparte eficiente de los diversos canales que ya están abiertos. Con AsiaPacifico se ha establecido una presencia y una red de acuerdos, pero todavía queda mucho por avanzar, partiendo por la profundización del dialogo político, la diversificación de la relación comercial -todavía muy determinada por el cobre- y un mayor conocimiento de los dinámicos procesos de desarrollo que hoy lideran el crecimiento económico mundial.

Pero se requiere una nueva mirada hacia América Latina que tenga en cuenta los logros y los problemas de estos años. El intento de participación en MERCOSUR partió con la asociación y luego perdió su fuerza cuando Chile empezó a negociar su TLC con Estados Unidos y el MERCosur se vio afectado por las crisis de algunos miembros. Las propuestas formuladas por el Presidente Lagos para conseguir una mayor coordinación de políticas macroeconómicas y para lograr una mayor certeza jurídica en el manejo de Mercosur cayeron en el vacío en una asociación dominada por los conflictos entre sus miembros más importantes y que no ha desarrollado instancias supranacionales. Estas siguen siendo condiciones para facilitar una incorporación más 
plena de Chile a esos procesos. UNASUR, por su parte, carece de la dimensión de integración comercial, no obstante ha sido un instrumento de contención de tendencias centrifugas y de solución de diferencias entre países de la zona. En ese contexto un diálogo más sustantivo con Brasil es indispensable, teniendo en cuenta no solo su notable crecimiento y su proyección internacional global como potencia emergente, sino el carácter de sus vínculos con los países de la región.

La búsqueda de nuevos acuerdos bilaterales con México se debilitó a mediados de los años 2000 y los acercamientos a Perú perdieron fuerza con la disputa por el límite marítimo. No deja de ser interesante la renovación de la propuesta de avanzar juntos con Colombia y México hacia el Pacífico que la Presidenta Bachelet formulara al comenzar el gobierno del Presidente García y que ahora impulsa el saliente gobierno peruano. La resolución de la Corte de La Haya puede abrir espacios para lograr la necesaria confluencia con los vecinos y dar espacio a una nueva iniciativa integradora.

La activa participación del capital privado chileno en varios países de la región-incluido Brasil- es un elemento insoslayable en el diseño de una nueva política hacia la región y puede servir de germen de integración al que atender.

En fin, la importancia permanente del principal vecino, Argentina, requiere esfuerzos crecientes y constantes para generar marcos homologables y proyectos comunes que recojan las preocupa- ciones de las zonas de frontera, pero que las viabilicen en una proyección entre las dos sociedades.

Una activa política latinoamericana es necesaria y hay que replantearla teniendo en cuenta los diferentes factores ya señalados. Para implementarla se debe contar con los elementos de poder blando que se mencionaran anteriormente, incluido un dialogo fluido con Estados Unidos con Europa y la consolidación de las relaciones con el Asia-Pacífico. Regional, subregional y aun bilateralmente es preciso definir agendas a cuyo trabajo debe destinarse una parte importante de los esfuerzos en coordinación con las otras dependencias del estado y con diversos actores de la sociedad chilena, pues los temas que deben ser objeto de esa agenda trascienden el ámbito de la política exterior.

\section{LA POLÍTICA EXTERIOR EN UN MUNDO GLOBAL}

La situación mundial ha cambiado en estos veinte años y la interdependencia generada por la globalización quedó claramente de manifiesto en la crisis mundial de 2008. La dimensión exterior de un país como Chile no solo necesita ser repensada regional sino globalmente. En este terreno Chile necesita acrecentar sus recursos de poder blando y trabajar con la región para poder tener voz en los asuntos que lo afectan. La decisión del Presidente Lagos de no apoyar una resolución en el Consejo de Seguridad que habría autorizado el uso de la fuerza 
en el caso de Irak, se constituyó en un destacado factor de independencia de la política exterior chilena que consiguió el respeto de la comunidad internacional y aumentar su prestigio.

Para acrecentar la influencia se debe fortalecer la participación chilena en los espacios multilaterales y promover ahí la creación e implementación de los regímenes internacionales que viabilicen la gobernabilidad de la globalización. En esta clave se debe considerar la participación en las operaciones de paz, el fortalecimiento de la no proliferación nuclear, la concreción nuevos acuerdos comerciales multilaterales y las reformas para la gobernabilidad del sistema internacional en su conjunto.

Chile es un país que depende de una activa economía global y que, por lo tanto, requiere de la paz y seguridad internacionales para su desarrollo. La participación en las operaciones de paz es una política que será definitoria del perfil internacional chileno en los próximos años ${ }^{21}$. Por eso para Chile el caso de la operación de paz en Haití no es solo importante por lo que pasa en ese

21 La dimensión militar es considerada tradicionalmente parte del poder duro. Ella no puede ser la base principal de la acción exterior de países pequeños, cuya capacidad siempre estará limitada en relación con países de mayores recursos. Con todo, esta dimensión no puede ser desdeñada. Una adecuada capacidad disuasiva puede ser una condición necesaria para mantener la paz. Esa capacidad debe ser incorporada a la función de seguridad internacional -vía operaciones de paz-y puede significar prestigio adicional para un país pequeño o mediano. país caribeño, sino porque lo muestra como potencia regional responsable. De ahí que no pueda plantearse el tema de la participación en la MINUSTAH solo teniendo en cuenta sus impactos en Haití -que son por cierto muy importantes- sino como muestra del accionar de Chile, país que está dispuesto a asumir responsabilidades más globales. No se puede reducir el tema a Haití; Chile necesita plantearse una acción más diversificada en las operaciones de paz en el ámbito de las Naciones Unidas. La experiencia de participación en la de paz de Bosnia-Herzegovina ha sido una decisión muy valorada en nuestras relaciones con Europa.

El fortalecimiento del régimen de no proliferación nuclear -especialmente el Protocolo Adicional al Régimen de Salvaguardias de la OIEA- y de otros regímenes de seguridad internacional, incluida la negociación sobre materiales fisionables -hoy bloqueada en la Conferencia de Desarme- son importantes para una país como Chile, que da gran importancia a la eliminación de las armas de destrucción masiva como elemento central de la seguridad internacional. El fortalecimiento de América Latina y el Caribe como zona libre de armas nucleares, y del régimen universal de no proliferación y de armas de destrucción masiva, los acuerdos para controlar la seguridad a nivel global, los regímenes de control de tecnologías duales y la cooperación para lograr estos propósitos deben consolidarse como parte del núcleo de la política exterior de seguridad de Chile. 
La política exterior chilena debería retomar la dimensión de seguridad humana y de responsabilidad de proteger, que fue impulsada especialmente a mediados de la década pasada ${ }^{22}$ y que une la idea de la seguridad internacional con la seguridad de las personas. Chile ha participado en el grupo de países afines $^{23}$ y existen potencialidades muy dinámicas entre estos conceptos y los valores internacionales que el país sustenta. Este tema debe vincularse con las preocupaciones sobre desarrollo social en el ámbito internacional que atravesaron los gobiernos de los Presidentes Aylwin y Frei (Cumbre de Desarrollo Social) Lagos (Objetivos de Desarrollo del Milenio e Iniciativa contra el Hambre y la Pobreza) y Bachelet (oDM en salud materno-infantil e Iniciativa contra el Hambre y la Pobreza) y articularse más eficazmente con la agenda de trabajo decente de la огт. La visión de desarrollo social, que incluye la disminución de la desigualdad, tiene una proyección internacional.

La experiencia y la historia reciente de Chile y las políticas públicas que le han permitido avanzar en los campos políticos, sociales y económicos deben ser compartidas de manera de aumentar el poder blando. Un papel importante en este sentido pueden desempañar actores no gubernamentales, portadores a nivel internacional de estas preocu-

22 La Canciller Soledad Alvear desarrollo el firme apoyo de Chile al trabajo dirigido por el ex Canciller australiano Gareth Evans.

23 La Red de Seguridad Humana y otros grupos en las Naciones Unidas. paciones. De ahí la importancia de fortalecer la interlocución y el trabajo de los formuladores de política exterior con el mundo no gubernamental, otorgando mayores recursos y visibilidad a esfuerzos que ya se han realizado puntualmente en relación con los temas de derechos humanos, democracia y de políticas sociales y económicas ${ }^{24}$. Los programas de Cooperación Internacional e Imagen País deberían converger en la maximización de este valioso recurso de presencia exterior.

Subrayar esfuerzos por la concreción de acuerdos comerciales internacionales globales será un paso congruente con la política implementada y significaría una nueva perspectiva para un proceso de desarrollo vinculado a una economía global abierta y con reglas predecibles: nuestra reconocida acción en el seno de la omc debería ser proyectada como parte más integral de nuestra política

24 Nos referimos aquí a experiencias de varias organizaciones no gubernamentales chilenas en Haití, por ejemplo, algunas que han contado con facilitación del aparato publico, pero que no han sido recogidas en el imaginario como parte de la acción exterior de Chile. Numerosas experiencias que van desde los intercambios sobre la transición política, la justicia transicional, los programas sociales, las reformas económicas y los modelos de políticas públicas, que se realizan ya sea desde diversos organismos del Estado, desde ámbitos académicos o desde consultorías privadas deberían estar también ligadas en el imaginario en un programa "Chile Comparte", una etiqueta que muestre la capacidad de ideas, políticas y planes que han permitido el desarrollo de la sociedad chilena y que forme parte de la cooperación chilena. 
exterior. La incorporación de Chile a la OCDE, a su vez, debería proporcionar herramientas para profundizar la modernización y crecimiento económico, indispensables si consideramos el carácter global de la competencia económica en el mundo de hoy.

Chile debe seguir trabajando en las ideas de gobernabilidad del sistema internacional que el Presidente Lagos levanto en Monterrey (2003), que Chile busco facilitar en el proceso de reforma de las Naciones Unidas y que después de la crisis económica de 2008 llevaron a fortalecer el rol del G-20. En este proceso, debe ser un objetivo de la política exterior jugar un papel en relación con este mecanismo y tener una visión más cabal y precisa de la reforma de los organismos internacionale ${ }^{25}$. Si las reformas implican incorporar las voces de todos los continentes en la construcción de las soluciones globales, es indispensable establecer formas de coordinación con los países latinoamericanos que participan en el G-20. Si esto no se logra, solo habrá una ampliación limitada de un mecanismo de decisiones oligopólico. La concreción de la reforma del Consejo

25 Es indispensable una coordinación más estrecha entre los Ministerios de Hacienda y Relaciones Exteriores. Las reformas a la gobernabilidad global han puesto el acento en los organismos financieros internacionales. El G-20 hoy aparece como la idea más concreta de cambio. Para aumentar la capacidad de acción de un país como Chile es indispensable una actuación más coordinada entre estos Ministerios en el ámbito internacional. de Seguridad debería mirarse a la luz de estos desarrollos. Es fundamental una reflexión profunda sobre estos temas que incidirán en los márgenes de acción internacional de Chile en las décadas que vienen.

La política exterior chilena hacia Estados Unidos y Canadá, hacia Europa y en relación al Asia Pacifico -incluidos China y Japón- ha tenido desarrollos espectaculares en estas dos décadas ${ }^{26}$. Su proyección -que trasciende el espacio de este trabajo- es fundamental para conseguir la inversión, los mercados y muy especialmente la inserción en las principales corrientes del desarrollo científico-tecnológico indispensable para avanzar en el mundo del siglo XXI. Estas tareas, por cierto, trascienden con mucho a la política exterior. Los modelos de colaboración público-privada -como lo ha sido la Fundación Chile y la Fundación Chilena del Pacífico-, el avance en la gestión de la colaboración

26 El Acuerdo de Libre Comercio con Canada (1997), el Acuerdo de Asociación con la Unión Europea (2003), el Acuerdo de Libre Comercio con la Asociación Europea de Libre Comercio (2004), el Acuerdo de Libre Comercio con los Estados Unidos de América (2004) y los acuerdos de Libre Comercio con la República de Corea (2004), con China (2006), con Japón (2007), con Singapur, Nueva Zelanda, y Brunei (P4) (2006), con Australia (2009) con Turquía (2010) y el Acuerdo Comercial con India (2007) son el resultado de un esfuerzo gigantesco de creación de reglas que han fijado un marco para nuestras relaciones con esos países y mercados que junto con los países latinoamericanos y del Caribe representan más del 90\% de nuestros mercados. 
científico-tecnológica y el desarrollo de las capacidades propias en estos ámbitos -como en el ya abonado terreno de la observación astronómica- son desafíos que deben vincular a la política exterior con otros ámbitos de las políticas públicas.

Si se piensa en un mundo global, Chile debe fortalecer su presencia selectiva- en otras importantes aéreas del planeta en que su política exterior ha comenzado a ser desarrollada solo en los últimos años o ha sido residual. El primer caso es el de la India -que ya ha empezado a avanzar promisoriamente- y Rusia, importantes países que presentan múltiples oportunidades para la interacción con un país como Chile y cuya relación debe desarrollarse. El segundo caso es el de países de África subsahariana, del mundo árabe y musulmán y del Asia. Una adecuada selección de prioridades debe abrir iniciativas acotadas, pero que permitan incrementar esos espacios, siguiendo los primeros pasos desarrollados por el gobierno de Bachelet. Experiencias como los intercambios en políticas sociales con Sudáfrica; una mayor vinculación de las múltiples consultorías que chilenos realizan en el exterior sobre la base de la experiencia de la transición a la democracia (políticas, de justicia transicional, de relaciones cívico-militares, etc.) que hoy podrían tener acogida en países árabes; intercambios sobre múltiples políticas publicas exitosas; y la apertura de nuevas oportunidades económicas en países que están teniendo altas tasas de crecimiento -como muchos del África hoy día- deberían ser realizadas más sistemáticamente.

La política exterior y el incremento de la influencia del país es clave para reforzar su inserción internacional y la capacidad de acción de la comunidad nacional (tanto de agentes públicos como privados) en un mundo cada vez más globalizado. Una línea de política exterior que subraye - especialmente en los ámbitos multilaterales- los valores de paz, derechos humanos y democracia, apoyada por una clara comprensión de los desarrollos internacionales y una prudente y constructiva acción exterior deben ser reforzadas.

Estos desafíos implican elevar sustantivamente la capacidad de diagnostico e información, así como la de comunicación no solo para la Cancillería -cuya modernización todavía es tarea pendiente- ${ }^{27}$, sino para el aparato del

27 Este cambio institucional fue un objetivo no alcanzado durante los gobiernos de la Concertación. La modernización supone la adecuación del instrumento a las necesidades requeridas para llevar adelante una determinada política. En un mundo de información abundante, especializada y en constante cambio es necesario contar con un aparato que pueda ir incorporando nuevas dimensiones y cuyo personal sea capaz de dominar nuevos «dossiers», no para convertirse en "especialistas», sino para desarrollar una capacidad de información y de negociación sustantiva sobre los temas. Es indispensable mejorar el nivel de formación analítica y de versatilidad para una diplomacia acorde con las nuevas dimensiones a abordar. En este sentido, no puede confundirse modernización con corporativismo. No deja de ser indicativo que una de las tareas fundamentales de estos 20 años -las negociaciones 
Carlos Portales • Desafíos para la política exterior...

Estado y para los actores nacionales que tengan un papel que jugar más allá de nuestras fronteras. La modernización del aparato publico y el mejoramiento sustancial de su coordinación con otros actores relevantes debe buscar maximizar la coordinación de las distintas avenidas de intercambio con el exterior en el mundo globalizado de la segunda década del siglo Xxi. comerciales internacionales- hayan sido realizadas por una combinación de profesionales y diplomáticos. Se requiere una modernización, que sea capaz de garantizar el mérito como base de una profesionalización permanente y flexible. Lo anterior requiere mayores recursos e inversio- nes, modestas en el contexto del presupuesto nacional, pero que son indispensables para renovar y modernizar una Cancillería que, coordinada con el aparato del Estado, deberá enfrentar los nuevos y variados desafios para la acción exterior de Chile. 